\title{
Nutrition in chronic obstructive pulmonary disease: A review
}

Gautam Rawal $^{1}$, Sankalp Yadav ${ }^{2}$

'Attending Consultant-Respiratory Intensive Care, Max Super Speciality Hospital, Saket, New Delhi, India; ${ }^{2}$ General Duty Medical Officer-II, Chest Clinic Moti Nagar, North Delhi Municipal Corporation, New Delhi, India

\section{ABSTRACT}

Cachexia and muscle wasting is a frequent but partly reversible complication in patients with chronic obstructive pulmonary disease (COPD), and affects the disease progression and prognosis. Weight loss in COPD is a consequence of increased energy requirements unbalanced by dietary intake. Nutritional supplement therapy has been shown to be effective for maintaining and improving the muscle strength and exercise tolerance in poorly nourished COPD patients, thereby decreasing morbidity and mortality. This mini review discusses the role of nutritional supplement therapy in the treatment of COPD.

Key words: cachexia, COPD, nutritional supplement therapy, under-nutrition

\section{INTRODUCTION}

Chronic obstructive pulmonary disease (COPD) as defined by The Global Initiative for Chronic Obstructive Lung Disease (GOLD) is characterized by airflow limitation that is usually progressive, partly reversible and associated with an enhanced chronic inflammatory response in the airways and the lungs to noxious stimuli. ${ }^{[1]}$ The global prevalence of COPD in adults aged 40 years and above is estimated to be approximately $9 \%$ to $10 \% \cdot{ }^{[2,3]}$ Worldwide, COPD is presently the fourth leading cause of death and may become the third leading cause by 2030 , as estimated by the World Health Organization (WHO) ${ }^{[4]}$ Considering the impact on the society's medico-economic burden by this disease, the preventive and therapeutic measures for the disorder are being relentlessly pursued.

The majority of the patients with severe COPD are lean, and frequently in a malnourished or undernourished state, referred to as "pulmonary cachexia syndrome" (PCS), which is characterized by loss of fat-free body mass causing muscle wasting. In fact, it is estimated to occur in $25 \%$ to $40 \%$ of COPD patients and is associated with an accelerated decline in functional status, carrying an unfavorable prognosis. ${ }^{[-7]}$ The muscle wasting in COPD not only leads to decreased skeletal muscle function associated with reduced exercise capacity, but is also a major determinant of mortality in COPD, independent of airflow obstruction. ${ }^{\left[{ }^{8,9]}\right.}$ Nutritional supplement therapy has been incorporated in the management of COPD patients since a long time and has shown good and promising results. ${ }^{[10]}$ This manuscript briefly discusses the PCS and the role of nutritional supplement therapy in the management of COPD.

\section{COPD AND UNDERNUTRITION}

Patients with advanced COPD are often noticed to have decreased body weight. Twenty-five percent to forty percent of all COPD patients have low body weight, with $25 \%$ of patients having moderate to severe weight loss and $35 \%$ of patients with extremely low fat-free mass (FFM) index. ${ }^{[5]}$ This is of great concern, as the decreased body weight in patients with COPD has been recognized as a poor-prognostic factor $^{[5-7]}$ with the survival time of about 2 
to 4 years in patients with severe disease who are lean with a forced expiratory volume \% in one second (FEV1\%) of less than $50 \%{ }^{[11]}$ It has also been observed that COPD patients with an initial body mass index (BMI) of less than $20 \mathrm{~kg} / \mathrm{m}^{2}$ or weight loss during the one-year followup period have a higher risk of acute exacerbations with a high mortality rate as compared to COPD patients with a BMI of $20 \mathrm{~kg} / \mathrm{m}^{2}$ or greater or no weight loss. ${ }^{[1]}$

\section{Causes of Undernutrition in COPD Patients}

The pulmonary cachexia syndrome in COPD patients is characterized by a weight loss of $5 \%$ to $10 \%$ of initial body weight, weight less than $90 \%$ of ideal body weight (IBW), or weight loss exceeding $5 \%$ in the past 3 to 12 months.

The exact pathogenesis of PCS still remains unclear, as a number of factors contribute to a progressive reduction in lean body mass. These include tissue hypoxia, disuse atrophy, changes in metabolism and caloric intake, oxidative stress, aging, inflammation, and medications (glucocorticoids) and malnutrition. ${ }^{[12,13]}$

\section{Metabolism and caloric intake}

It has been demonstrated that in COPD patients the resting energy expenditure (REE) is increased. ${ }^{[12-14]}$ Many of the COPD patients are in a state of hyper metabolism; that is, they consume more calories per kilogram on calorimetric measures, likely because of the increased work of breathing. ${ }^{[12-14]}$ Despite this, COPD patients have a reduced dietary intake due to loss of appetite because of decreased general physical activity, a tendency towards depression, or dyspnea while eating. ${ }^{[15]}$

\section{Systemic inflammation}

COPD is recognized as a systemic inflammatory disorder associated with increased production of inflammatory cytokines such as interleukin (IL)-6, IL-8, and tumor necrosis factor (TNF) $-\alpha$, and chemokines. ${ }^{[16,17]}$ Koehler et al..$^{[18]}$ in 2007 demonstrated a significant correlation between increased levels of IL- 6 and decreased appetite. The studies done by Ouchi et al. ${ }^{[19]}$ and Breyer et al. ${ }^{[20]}$ showed dysregulation of adipokines in patients of COPD, giving rise to low-grade systemic inflammation. Görek et al. ${ }^{[21]}$ demonstrated a correlation between the elevated serum TNF- $\alpha$ levels and weight loss in COPD patients.

\section{Hypoxia}

At the cellular level an adequate tissue oxygenation implies appropriate matching of oxygen demand and delivery. The oxygen demands increase in patients with advanced COPD due to the increased work of breathing, though the ability to respond to these increased demands is limited. This phenomenon is commonly seen in patients with emphysema, where the severity of the airflow obstruction is linearly related to impaired left ventricular filling, reduced stroke volume, and lower cardiac output. ${ }^{[22]}$ In this case the body maintains the blood flow to the critical sites such as the heart, central nervous system, and the ventilatory muscles, while peripheral tissues including the skeletal muscles develop hypoxia and nutrient deficit. ${ }^{[23]}$

\section{Medications}

Glucocorticoids used to treat COPD exacerbations, play an important role in muscle wasting syndromes as they inhibit protein synthesis and promote protein catabolism, despite increasing the appetite. This muscle wasting side effect of glucocorticoids (glucocorticoid-induced myopathy) is thought to be dose-related and a dose greater than $60 \mathrm{mg} /$ day may lead to reduction in respiratory muscle strength. ${ }^{[2,25]}$ Patients with COPD also lose peripheral muscle oxidative phenotype, which makes their muscles less energy efficient and more prone to oxidative stress and thus augmenting the loss of muscle mass. ${ }^{[24,25]}$

\section{Aging}

COPD is a disease of the elderly. Body composition changes with aging, and the elderly progressively show loss of lose fat-free body mass (primarily muscle tissue) causing the decline in muscle strength leading to reduced exercise capacity.

\section{Management}

The association of weight loss and muscle wasting in COPD patients have been shown to increase morbidity and mortality. Nutrition supplement therapy along with exercise is advised in such patients.

Screening for malnutrition: The patients with COPD should be monitored for the presence of pulmonary cachexia or weight loss approximately every 6 to 12 months or at the time of routine visits. Patients are assessed for a weight lesser than $90 \%$ of ideal body weight or BMI $\leq 20$.

\section{General measures}

(1) Reducing the work of breathing by optimizing the lung function. This reduces the caloric requirement and expenditure and also increases patient's adherence to exercise.

(2) Regular exercise: This not only stimulates appetite, but also improves the effectiveness of nutritional therapy. ${ }^{[2]}$

\section{Nutritional interventions}

Nutritional supplement therapy has been proved to be effective for maintaining and improving the muscle strength and exercise tolerance in poorly nourished COPD patients and are identified as a modifiable risk factor to chronic disease development and progression. ${ }^{[27,28]}$ (1) Cai et al. ${ }^{[29]}$ 
Rawall and Yadav: Nutrition in chronic obstructive pulmonary disease: A review

in 2003 demonstrated a significant improvement in pulmonary function in COPD patients with a high-fat, low carbohydrate diet as compared with the traditional high carbohydrate diet. (2) Fruits and vegetable intake has been found beneficial in chronic and acute respiratory conditions as they contain antioxidants, minerals, vitamins, flavonoids, phytochemicals, and fiber. ${ }^{[30]}$ (3) Omega-3 polyunsaturated fatty acids (PUFA) have been shown to have an antiinflammatory effect and may be of benefit in a chronic inflammatory condition like COPD and also in malnourished patients. ${ }^{[1,32]}$ (4) Vitamin D: The serum levels of vitamin D have been found to be low in patients with COPD ${ }^{[33]}$, and its deficiency has been related to early progression of COPD. ${ }^{[34]}$ Various studies have shown a positive relation of vitamin $\mathrm{D}$ supplementation in patients with COPD. This may be due to the immune-modulatory effect of vitamin $\mathrm{D}$, and it also helps to decrease the myopathy/muscle weakness. ${ }^{[3]}$ (5) Vitamin $\mathrm{C}$ and $\mathrm{E}$ supplementation also plays a promising role in alleviating COPD symptoms. ${ }^{[27]}$ (6) Small frequent meals that are dense in nutrient content with sufficient calories that meet basal energy expenditure and induce weight gain, meals that require little preparation (e.g. liquid nutritional supplements, microwaveable), resting before meals, and taking daily dose of multivitamins are recommended.

\section{CONCLUSION}

This review shows that undernutrition in patients with COPD is an important risk factor for poor quality of life and physical exercise performance, with increased risk of exacerbations. There is enough evidence to show that in patients with COPD a well-balanced diet is beneficial, not only for the potential gains in the pulmonary status, but also for lowering metabolic and cardiovascular risks. ${ }^{[36]}$ The nutritional supplement therapy not only improves undernutrition in COPD patients, but also is beneficial in the prevention of the development, progression, and exacerbation of COPD, and suppresses the inflammatory response. In order to increase the overall survival rate and decrease morbidity in patients with COPD, the nutritional aspect should be incorporated into the management of this disease.

\section{Conflict of Interest}

None declared.

\section{REFERENCES}

1. Global strategy for the diagnosis, management, and prevention of chronic obstructive pulmonary disease: Revised 2015. Global Initiative for Chronic Obstructive Lung Disease (GOLD). Available at: www. goldcopd.org. Last accessed on November 2, 2015.

2. Halbert RJ, Natoli JL, Gano A, Badamgarav E, Buist AS, Mannino DM. Global burden of COPD: systematic review and meta-analysis. Eur Respir J 2006; 28:523-32.
3. Mannino DM, Buist AS. Global burden of COPD: risk factors, prevalence, and future trends. Lancet 2007; 370: 765-73.

4. Decramer M, Janssens W, Miravitlles M. Chronic obstructive pulmonary disease. Lancet 2012; 379: 1341-51.

5. Vermeeren MA, Creutzberg EC, Schols AM, Postma DS, Pieters WR, Roldaan AC, et al. Prevalence of nutritional depletion in large out-patient population of patients with COPD. Respir Med 2006; 100: 1349-55.

6. Wagner PD. Possible mechanisms underlying the development of cachexia in COPD. Eur Respir J 2008; 31: 492-501.

7. Schols AM. Nutrition in chronic obstructive pulmonary disease. Curr Opin Pulm Med 2000; 6: 110-5.

8. Vestbo J, Prescott E, Almdal T, Dahl M, Nordestgaard BG, Andersen T, et al. Body mass, fat-free body mass, and prognosis in patients with chronic obstructive pulmonary disease from a random population sample: findings from the Copenhagen City Heart Study. Am J Respir Crit Care Med 2006;173:79-83.

9. Scheepers CA, Wouters EF. Body composition and mortality in chronic obstructive pulmonary disease. Am J Clin Nutr 2005; 82:53-9.

10. Collins PF, Stratton RJ, Elia M. Nutritional support in chronic obstructive pulmonary disease: A systematic review and meta-analysis. Am J Clin Nutr 2012; 95: 1385-95.

11. Hallin R, Koivisto-Hursti UK, Lindberg E, Janson C. Nutritional status, dietary energy intake and the risk of exacerbations in patients with chronic obstructive pulmonary disease (COPD). Respir Med 2006; 100: $561-7$.

12. Langen RC, Gosker HR, Remels AH, Schols AM. Triggers and mechanisms of skeletal muscle wasting in chronic obstructive pulmonary disease. Int J Biochem Cell Biol 2013; 45: 2245-56.

13. Remels AH, Gosker HR, Langen RC, Schols AM. The mechanisms of cachexia underlying muscle dysfunction in COPD. J Appl Physiol (1985) 2013; 114: 1253-62.

14. Schols AM, Fredrix EW, Soeters PB, Westerterp KR, Wouters EF. Resting energy expenditure in patients with chronic obstructive pulmonary disease. Am J Clin Nutr 1991; 54: 983-7.

15. Grönberg AM, Slinde F, Engström CP, Hulthén L, Larsson S. Dietary problems in patients with severe chronic obstructive disease. J Hum Nutr Diet 2005; 18: 445-52.

16. Gan WQ, Man SF, Senthilselvan A, Sin DD. Association between chronic obstructive pulmonary disease and systemic inflammation: A systematic review and a meta-analysis. Thorax 2004; 59: 574-80.

17. De Godoy I, Donahoe M, Calhoun WJ, Mancino J, Rogers RM. Elevated TNF-a production by peripheral blood monocytes of weight-losing COPD patients. Am J Respir Crit Care Med 1996; 153: 633-7.

18. Koehler F, Doehner W, Hoernig S, Witt C, Anker SD, John M. Anorexia in chronic obstructive pulmonary disease-association to cachexia and hormonal derangement. Int J Cardiol 2007; 119: 83-9.

19. Ouchi N, Parker JL, Lugus JJ, Walsh K. Adipokines in inflammation and metabolic disease. Nat Rev Immunol 2011; 11: 85-97.

20. Breyer MK, Rutten EP, Locantore NW, Watkins ML, Miller BE, Wouters EF. Dysregulated adipokine metabolism in chronic obstructive pulmonary disease. Nat Rev Immunol 2011; 11: 85-97.

21. Görek Dilektaşli A, Ulubay G, Bayraktar N, Eminsoy I, Oner Eyüboğlu F. The effects of cachexia and related components on pulmonary functions in patients with COPD. Tuberk Toraks 2009; 57: 298-305.

22. Barr RG, Bluemke DA, Ahmed FS, Carr JJ, Enright PL, Hoffman EA, et al. Percent emphysema, airflow obstruction, and impaired left ventricular filling. N Engl J Med 2010; 362: 217-27.

23. Donahoe M. Nutritional support in advanced lung disease. The pulmonary cachexia syndrome. Clin Chest Med 1997; 18: 547-61.

24. Balkom van RH, Heijden van der HF, Herwaarden van CL, Dekhuijzen PN. Corticosteroid induced myopathy of the respiratory muscles. Neth J Med 1994; 45: 114-22.

25. Gosker HR, Wouters EF, van der Vusse GJ, Schols AM. Skeletal muscle dysfunction in chronic obstructive pulmonary disease and chronic heart 
failure: underlying mechanisms and therapy perspectives. Am J Clin Nutr 2000;71:1033-47.

26. Schols AM, Wouters EF. Nutritional abnormalities and supplementation in chronic obstructive pulmonary disease. Clin Chest Med 2000; 21: 753-62.

27. Berthon BS, Wood LG. Nutrition and Respiratory Health-Feature Review. Nutrients 2015; 7: 1618-43.

28. Ferreira IM, Brooks D, White J, Goldstein R. Nutritional supplementation for stable chronic obstructive pulmonary disease. Cochrane Database Syst Rev 2012; 12:CD000998.

29. Cai B, Zhu Y, Ma Yi, Xu Z, Zao Yi, Wang J, et al. Comer G.M. Effect of supplementing a high-fat, low-carbohydrate enteral formula in COPD patients. Nutrition 2003; 19: 229-32.

30. Shaheen SO, Jameson KA, Syddall HE, Aihie Sayer A, Dennison EM, Cooper $\mathrm{C}$, et al. The relationship of dietary patterns with adult lung function and COPD. Eur Respir J 2010; 36: 277-84.

31. Rawal G, Yadav S, Shokeen P, Nagayach S. Medical nutrition therapy for the critically ill. Int J Health Sci Res 2015; 5: 384-93.

32. Thies F, Miles EA, Nebe-von-Caron G, Powell JR, Hurst TL, Newsholme $\mathrm{EA}$, et al. Influence of dietary supplementation with long-chain n-3 or n-6 polyunsaturated fatty acids on blood inflammatory cell populations and functions and on plasma soluble adhesion molecules in healthy adults. Lipids 2001; 36:1183-93.

33. Persson LJ, Aanerud M, Hiemstra PS, Hardie JA, Bakke PS, Eagan TM. Chronic obstructive pulmonary disease is associated with low levels of vitamin D. PLoS One 2012; 7: e38934.

34. Sundar IK, Hwang JW, Wu S, Sun J, Rahman I. Deletion of vitamin D receptor leads to premature emphysema/COPD by increased matrix metalloproteinases and lymphoid aggregates formation. Biochem Biophys Res Commun 2011; 406: 127-33.

35. Rawal G, Yadav S, Shokeen P. Health and the vitamin D. Int J Health Sci Res 2015; 5: 416-23.

36. Schols AM, Ferreira IM, Franssen FM, Gosker HR, Janssens W, Muscaritoli $\mathrm{M}$, et al. Nutritional assessment and therapy in COPD: a European Respiratory Society statement. Eur Respir J 2014; 44: 1504-20.

How to cite this article: Rawal G, Yadav S. Nutrition in chronic obstructive pulmonary disease: A review. J Transl Intern Med 2015; $151-154$. 